\title{
Opioid Receptors in the Midbrain Periaqueductal Gray Regulate Extinction of Pavlovian Fear Conditioning
}

\author{
Gavan P. McNally, Michael Pigg, and Gabrielle Weidemann \\ School of Psychology, The University of New South Wales, Sydney, New South Wales 2052, Australia
}

\begin{abstract}
Four experiments studied the role of opioid receptors in the midbrain periaqueductal gray matter (PAG), an important structure eliciting conditioned fear responses, in the extinction of Pavlovian fear. Rats received pairings of an auditory conditioned stimulus (CS) with a foot shock unconditioned stimulus (US). The freezing conditioned response (CR) elicited by the CS was then extinguished via nonreinforced presentations of the CS. Microinjection of the opioid receptor antagonist naloxone into the ventrolateral PAG (vlPAG) before nonreinforced CS presentations impaired development of extinction, but such microinjections at the end of extinction did not reinstate an already extinguished freezing CR. This role for opioid receptors in fear extinction was specific to the vlPAG because infusions of naloxone into the dorsal PAG did not impair fear extinction. Finally, the impairment of fear extinction produced by vlPAG infusions of naloxone was dose-dependent. These results show for the first time that the midbrain PAG contributes to fear extinction and specifically identify a role for vlPAG opioid receptors in the acquisition but not the expression of such extinction. Taken together with our previous findings, we suggest that, during fear conditioning, activation of vlPAG opioid receptors contributes to detection of the discrepancy between the actual and expected outcome of the conditioning trial. vlPAG opioid receptors regulate the learning that accrues to the CS and other stimuli present on a trial because they instantiate an associative error correction process influencing US information reaching the site of CS-US convergence in the amygdala. During nonreinforcement, this vlPAG opioid receptor contribution signals extinction.
\end{abstract}

Key words: learning; memory; extinction; fear conditioning; periaqueductal gray; opioid receptor

\section{Introduction}

Exposed to pairings of a conditioned stimulus (CS) with a foot shock unconditioned stimulus (US), rats learn about the relationship between the CS and US. They exhibit this learning when reexposed to the CS in diverse but correlated fear conditioned responses (CRs), including freezing, hypoalgesia, potentiated startle, and increased blood pressure (Davis 1992; Fendt and Fanselow, 1999; Maren, 2001). This learning is mediated by glutamatergic neurotransmission in the amygdala. Specifically, evidence suggests that activation of NMDA receptors in the amygdala basolateral nucleus (BLa) detects the CS-US conjunction. This activation, in turn, initiates a variety of signal transduction cascades (e.g., $\mathrm{Ca}^{2+}$ and cAMP) to result in synaptic plasticity (for review, see Fanselow and LeDoux, 1999; Maren, 2001). The consequence of this plasticity is that the CS gains access to the central nucleus of the amygdala (CeA) to elicit fear CRs via projections to the brainstem.

The fear acquired via CS-US pairings can be reduced or extinguished by exposures to the CS in the absence of the US. Such extinction does not erase the CS-US association. Rather, the original association remains intact after extinction, and a mask is

Received March 16, 2004; revised June 6, 2004; accepted June 7, 2004.

This research was supported by Australian Research Council Discovery Project Grant DP0343808 (G.P.M.). We thank Fred Westbrook, Rick Richardson, and Pascal Carrive for helpful discussions.

Correspondence should be addressed to Dr. Gavan P. McNally at the above address. E-mail: g.mcnally@unsw.edu.au.

D0I:10.1523/JNEUROSCI.1828-04.2004

Copyright $\odot 2004$ Society for Neuroscience $\quad 0270-6474 / 04 / 246912-08 \$ 15.00 / 0$ imposed on it. Recent research has begun to identify the neural mechanisms for fear extinction and the neurobiological mask imposed on the original association. For example, fear extinction, like fear acquisition, depends on NMDA receptor activity and associated signal transduction cascades in the BLa because it is prevented by BLa administrations of NMDA receptor antagonists and facilitated by NMDA receptor partial agonists (Falls et al. 1992; Walker et al., 2002). There is evidence that the medial prefrontal cortex provides the mask that restricts expression of fear CRs after extinction because its stimulation mimics (Milad and Quirk, 2002) and its destruction impairs (Morgan et al., 1993) long-term fear extinction. However, knowledge of the neural mechanisms for extinction of Pavlovian fear conditioning remains incomplete.

The midbrain periaqueductal gray (PAG) receives extensive projections from the CeA and controls expression of freezing as a CR (Fanselow, 1991; Carrive, 1993). Manipulations that increase PAG activity (e.g., electrical or chemical stimulation) elicit freezing (Vianna et al., 2001), whereas manipulations that decrease PAG activity prevent freezing as a CR (De Oca et al., 1998; Amorapanth et al., 1999; Walker and Carrive, 2003). Moreover, expression of conditioned freezing is associated with increased PAG neuronal activation (Carrive et al., 1997). Given this role for the PAG in eliciting the freezing CR, it follows that the PAG might be an important site for extinction of conditioned freezing. In the present experiments, we tested this possibility. In particular, we studied the role of PAG opioid receptors in fear extinction because we have recently shown that opioid receptors regulate fear 
extinction (McNally and Westbrook, 2003). The PAG is rich in opioid receptors and has been implicated in many of the effects of opioid receptor agonists and antagonists. The aim of the present experiments, therefore, was to study the effects of PAG microinjections of an opioid receptor antagonist on extinction of Pavlovian fear conditioning.

\section{Materials and Methods Subjects}

The subjects were experimentally naive adult male Wistar rats (220-280 gm) obtained from a commercial supplier (Gore Hill Research Laboratories, Sydney, New South Wales, Australia). After arrival, rats were housed in groups of six to eight in plastic cages maintained on a $12 \mathrm{hr}$ light/dark cycle (lights on at 7 A.M.) and were allowed access to water and food ad libitum. The rats were handled (1-2 min/d per rat) for $3 \mathrm{~d}$ before surgery to habituate them to the experimenter. The procedures used were approved by the Animal Ethics Committee at The University of New South Wales and were conducted in accordance with the National Institutes of Health Guidelines for the Care and Use of Laboratory Animals (publication DHHS NIH 86-23).

\section{Surgery and histology}

Rats were injected intraperitoneally with a $1.3 \mathrm{ml} / \mathrm{kg}$ dose of the anesthetic ketamine (Ketapex; Apex Laboratories, Sydney, New South Wales, Australia) at a concentration of $100 \mathrm{mg} / \mathrm{ml}$ and with a $0.3 \mathrm{ml} / \mathrm{kg}$ dose of the muscle relaxant xylazine (Rompun; Bayer, Sydney, New South Wales, Australia) at a concentration of $20 \mathrm{mg} / \mathrm{ml}$. Each rat was placed in the stereotaxic apparatus (model 900; Kopf, Tujunga, CA) while maintaining the incisor bar at $\sim 3.3 \mathrm{~mm}$ below horizontal to achieve a flat skull position. A 26 gauge guide cannula (Plastics One, Roanoke, VA) was implanted into the PAG. For experiments 1, 2, and 4 the right ventrolateral PAG (vlPAG) was targeted so that the tip of the guide cannula was positioned $5.6 \mathrm{~mm}$ below lambda through a hole drilled $0.1 \mathrm{~mm}$ anterior to and $0.8 \mathrm{~mm}$ lateral to lambda. For experiment 3 the right dorsal PAG (dPAG) was targeted so that the tip of the guide cannula was positioned $4.4 \mathrm{~mm}$ below lambda through a hole drilled $0.6 \mathrm{~mm}$ anterior to and 0.8 $\mathrm{mm}$ lateral to lambda. We implanted the cannula into only one hemisphere to reduce the possible extent of damage to the PAG and overlying blood vessels. The right PAG was chosen to facilitate comparison with previous experiments studying the role of opioid receptors in the amygdala in fear acquisition (Good and Westbrook, 1995). The guide cannula was fixed in position with dental cement and anchored by jeweler's screws. A dummy cannula was kept in the guide at all times except during microinjections. Immediately after surgery, rats were injected intraperitoneally with a prophylactic $0.3 \mathrm{ml}$ dose of a $300 \mathrm{mg} / \mathrm{ml}$ solution of procaine penicillin and subcutaneously with $0.1 \mathrm{ml}$ of a $100 \mathrm{mg} / \mathrm{ml}$ cephazolin sodium. Rats were allowed $7 \mathrm{~d}$ to recover from surgery, during which time they were handled and weighed daily.

At the conclusion of the experiments, rats were given an overdose of sodium pentobarbital, and their brains were removed. Unfixed brains were sectioned coronally at $40 \mu \mathrm{m}$ through the PAG using a cryostat. Every fourth section was collected on a glass slide and subsequently stained with cresyl violet. Cannula placements were verified using the boundaries defined by Paxinos and Watson (1998). The sections were examined under a microscope by a trained observer unaware of the subjects' group designations. The data of any rat were excluded from the statistical analysis if the cannula tip was outside the PAG, or if the region had sustained extensive damage. Across experiments, there was little evidence of damage to the PAG caused by the 26 gauge guide cannula.

\section{Behavioral apparatus}

Conditioning and testing were conducted in a set of four identical chambers [24 (length) $\times 30$ (width) $\times 21$ (height $) \mathrm{cm}]$. The front and rear walls of these chambers as well as the hinged lid were constructed of clear Perspex, and the end walls were made of stainless steel. The floor in each chamber consisted of stainless steel rods, $4 \mathrm{~mm}$ in diameter, spaced 15 $\mathrm{mm}$ apart (center to center). Each chamber stood $2 \mathrm{~cm}$ above a tray of paper pellet bedding (Fibercycle, Mudgeeraba, Queensland, Australia). The chambers were cleaned with water, and the bedding underneath the chambers was changed between rats. These four chambers were located individually within sound-attenuating boxes that were painted white. The US was a $1 \mathrm{sec} 0.8 \mathrm{~mA}$ unscrambled AC $50 \mathrm{~Hz}$ shock from a constantcurrent generator that was delivered to the floor of each chamber. The current available to each floor could be adjusted using an in-line milliampere meter. The CS was a $10 \mathrm{sec} 74 \mathrm{~dB}$ (A scale) $20 \mathrm{~Hz}$ clicker delivered through speakers mounted in the ceiling of each box. Digital video cameras were mounted on the rear wall of each box and connected to a digital multiplexer in an adjacent room that, in turn, was connected to a video recorder. The stimuli used for conditioning were controlled by a computer (LabView; National Instruments, Austin, TX).

\section{Behavioral testing procedures}

Experiment 1: role of opioid receptors in vlPAG in acquisition and expression of fear extinction. On Day 0 of the experiment, rats were transported to the laboratory and placed in the conditioning chambers. Ten and 15 min after placement in the chamber, rats received a 10 sec presentation of the auditory CS that coterminated with delivery of the $1 \mathrm{sec} 0.8 \mathrm{~mA}$ foot shock. Rats were removed from the chamber 60 sec after the second foot shock. Across days $1-5$, rats were transported to the laboratory and microinjected. Rats in group naloxone $(n=10)$ were microinjected with naloxone $(2.5 \mu \mathrm{g} / 0.5 \mu \mathrm{l}, 6.32 \mathrm{~nm}$; Sigma, St Louis, $\mathrm{MO})$, whereas rats in group saline $(n=10)$ were microinjected with $0.9 \%(\mathrm{w} / \mathrm{v})$ sterile saline $(0.5 \mu \mathrm{l})$. For microinjections, a 33 gauge microinjection cannula was inserted into the guide cannula and connected to a $25 \mu$ l glass syringe operated by an infusion pump. The microinjection cannula projected an additional $1 \mathrm{~mm}$ ventral to the tip of the guide cannula. Drugs were infused over a 2 min period, and the microinjection cannula was left in place for an additional $1 \mathrm{~min}$ to permit diffusion of the injectate. All rats were then placed in the conditioning chamber. Four minutes later, the auditory CS was presented continuously for $10 \mathrm{~min}$. Rats were then returned to their home cages. On day 6, rats were transported to the laboratory and were placed in the conditioning chambers for the drugfree test. Four minutes after placement in the chamber, the auditory CS was presented for $10 \mathrm{~min}$. Rats were then returned to their home cages. On day 7, rats were transported to the laboratory for a crossover test. On arrival, rats received a microinjection as described above, with the important difference being that rats in group saline were now microinjected with naloxone $(2.5 \mu \mathrm{g} / 0.5 \mu \mathrm{l}, 6.32 \mathrm{nM})$, whereas rats in group naloxone were now microinjected with saline $(0.5 \mu \mathrm{l})$. Immediately after microinjection, rats were placed in the conditioning chambers for the crossover test. Four minutes after placement in the chamber, the auditory CS was presented for $10 \mathrm{~min}$. Rats were then returned to the home cages.

Experiment 2: role of vlPAG opioid receptors in extinction of conditioned fear. On day 0 of the experiment, rats were transported to the laboratory and placed in the conditioning chambers. Ten minutes after placement in the chambers, rats received a single $10 \mathrm{sec}$ presentation of the auditory CS that coterminated with delivery of the $1 \mathrm{sec} 0.8 \mathrm{~mA}$ foot shock. Rats were removed from the chamber $60 \mathrm{sec}$ later. Across days 1 and 2, rats were transported to the laboratory and received microinjections into the vlPAG. Rats in group naloxone $(n=8)$ were microinjected with naloxone $(2.5 \mu \mathrm{g} / 0.5 \mu \mathrm{l}, 6.32 \mathrm{~nm})$, whereas rats in group saline $(n=8)$ were microinjected with saline $(0.5 \mu \mathrm{l})$. For microinjections, a 33 gauge microinjection cannula was inserted into the guide cannula and connected to a $25 \mu$ l glass syringe operated by an infusion pump. The microinjection cannula projected an additional $1 \mathrm{~mm}$ ventral to the tip of the guide cannula. Drugs were infused over a $2 \mathrm{~min}$ period, and the microinjection cannula was left in place for an additional $1 \mathrm{~min}$ to permit diffusion of the injectate. All rats were then placed in the conditioning chamber. After 2 $\mathrm{min}$, the auditory CS was presented for $2 \mathrm{~min}$. This $2 \mathrm{~min}$ CS presentation was repeated an additional seven times at 2 min interstimulus intervals so that by the end of this session, rats had received eight nonreinforced 2 min presentations of the CS, each separated by $2 \mathrm{~min}$. Rats were then returned to their home cages. On day 3 rats were transported to the laboratory and were placed in the conditioning chambers for the drugfree test. After $2 \mathrm{~min}$, the auditory CS was presented for $2 \mathrm{~min}$. This $2 \mathrm{~min}$ CS presentation was repeated an additional three times at 2 min interstimulus intervals so that by the end of this test, rats had received four 
nonreinforced $2 \mathrm{~min}$ presentations of the CS, each separated by $2 \mathrm{~min}$. Rats were then returned to their home cages.

Experiment 3: role of APAG opioid receptors in extinction of conditioned fear. The procedure for experiment 3 was identical to that for experiment 2 with the single exception that rats received microinjections of naloxone (group naloxone, $n=8$ ) or saline (group saline, $n=8$ ) into the dPAG on days 1 and 2.

Experiment 4: dose-response properties of vlPAG opioid receptor contributions to extinction of conditioned fear. The procedure for experiment 4 was identical to that for experiment 2 with the exception that rats received microinjections of 5 (12.6 nM), 0.5 (1.26 nM), 0.05 (0.126 nM), or $0.0(0 \mathrm{nM}) \mu \mathrm{g}$ of naloxone ( $n=8$ per dose) before extinction training on days 1 and 2 .

\section{Data analysis}

Performance during conditioning and testing was videotaped. The rats were scored every $4 \mathrm{sec}$ as either freezing (defined as the absence of all movement other than that required for breathing) or not freezing. The percentage of these observations scored as freezing was then calculated. The videotapes were scored by two observers, one of whom was unaware of group allocation. The unaware observer scored a random sample of $25 \%$ of the animals. The inter-rater reliabilities, i.e., the correlation between each observer's ratings of the percentage of observations scored as freezing for each rat, consistently exceeded 0.85 in all experiments. The data were analyzed by means of a planned orthogonal contrast testing procedure adopting a multivariate approach to repeated measures where necessary (O'Brien and Kaiser, 1985). The type I error rate $(\alpha)$ was controlled at 0.05 for each contrast tested.

\section{Results}

Experiment 1: role of opioid receptors in vlPAG in acquisition and expression of fear extinction

We have shown previously that opioid receptors regulate the extinction of Pavlovian fear conditioning (McNally and Westbrook, 2003). In those experiments, rats received a single pairing of an auditory CS with a foot shock US. The fear (freezing) that had accrued to the CS was then extinguished. Injection of naloxone before this extinction significantly impaired the development of extinction. This impairment was mediated by opioid receptors in the brain and was not observed when naloxone was injected after extinction training. Finally, an injection of naloxone on the test failed to reinstate extinguished responding that had already accrued to the CS. The aim of experiment 1 was to determine whether a similar impairment of extinction would occur when the effects of naloxone were restricted to the vlPAG.

Rats were trained to fear an auditory CS via pairing with a foot shock. The fear that had accrued to that CS was then extinguished over five daily $10 \mathrm{~min}$ presentations of the CS. For half the rats, this extinction training occurred after microinjection of naloxone into the vlPAG, whereas for the remainder, it occurred after microinjection of saline. Rats were then tested for their fear reactions. The first test was conducted drug-free. The second test was a crossover test such that rats that had been extinguished after infusions of naloxone into the PAG were now tested after infusions of saline, whereas rats that had been extinguished after infusions of saline into the PAG were now tested after infusions of naloxone.

\section{Histology}

Figure $1 A$ shows the location of microinjection tips for rats in experiment 1 . Two animals in each group were excluded from the experiment because of incorrect cannula placement. Thus, 16 animals were included in the analyses (group saline, $n=8$; group naloxone, $n=8)$.
A.

B.
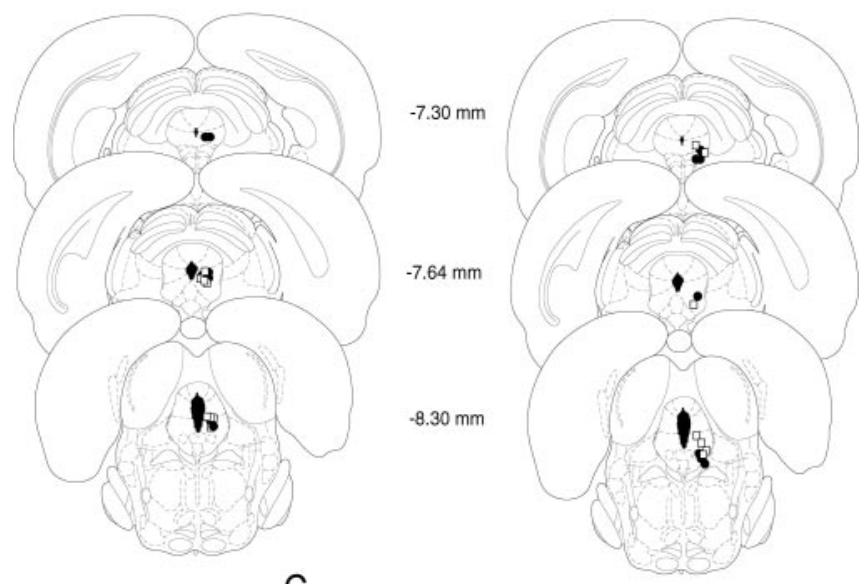

C.

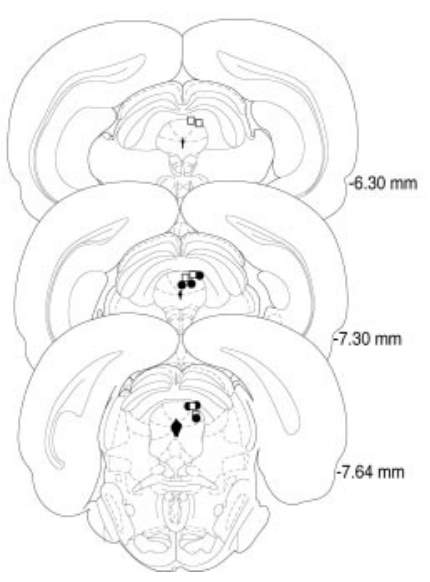

Figure 1. Cannula placement in the periaqueductal gray. Illustrations of injection cannula placements in the periaqueductal gray are shown for experiment $1(A)$, experiment $2(B)$, and experiment 3 (C). Placements represented are from all rats included in the final analysis (open squares, saline; filled circles, naloxone). Atlas templates were adapted from Paxinos and Watson (1998) (distances in millimeters from bregma).

\section{Behavior}

Figure $2 A$ shows the mean \pm SEM levels of freezing in 2 min blocks across the $5 \mathrm{~d}$ of extinction training. Figure $2 B$ shows freezing during the $4 \mathrm{~min}$ immediately before the first CS on day 1 of extinction, as well as the average freezing per day across the $5 \mathrm{~d}$ of extinction training (Extinction) and on the 2 test days (Test I, Test II). Inspection of Figure 2 indicates that microinjections of naloxone into the vlPAG did not alter levels of contextual freezing observed during the $4 \mathrm{~min}$ pre-CS period on day 1 . Indeed, there was no statistically significant difference between groups in levels of pre-CS freezing $\left(F_{(1,14)}<1 ; p>0.05\right)$. The 10 min presentations of the CS across days 1-5 resulted in the extinction of conditioned freezing so that there was a significant linear decrease in freezing across the $5 \mathrm{~d}$ of extinction training $\left(F_{(1,14)}=102.8 ; p<\right.$ $0.0001)$. Importantly, this extinction was retarded by the vlPAG microinjections of naloxone. Averaged across days, rats in group naloxone showed significantly more freezing during extinction than rats in group saline $\left(F_{(1,14)}=19.7 ; p<0.0001\right)$. There was, however, no interaction between these two contrasts.

On the first test day (test I, drug-free), rats were simply returned to the test chambers and were presented with the CS for 10 min in the absence of any drug infusions. The statistical analysis confirmed that there was no significant difference between 
A

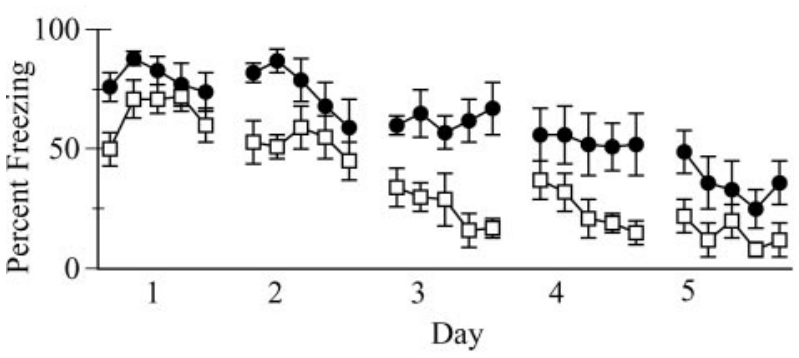

B

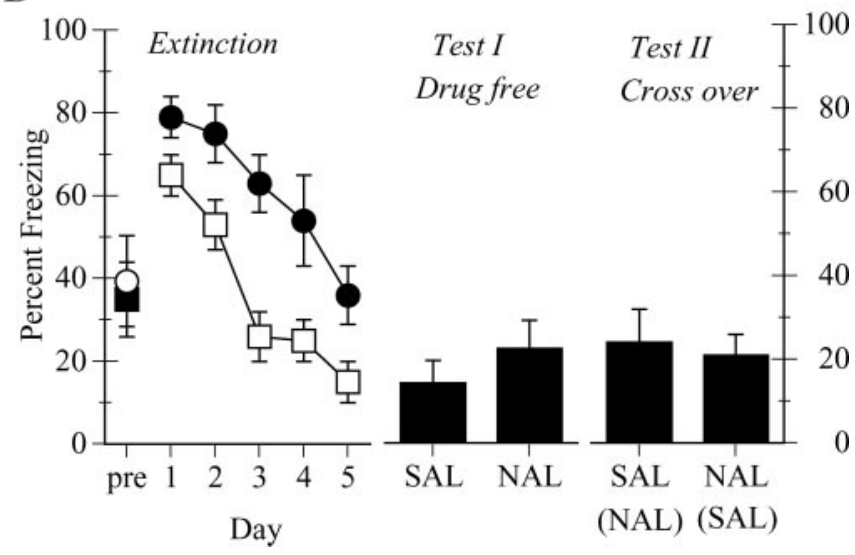

Figure 2. Role of opioid receptors in vIPAG in extinction of conditioned freezing (experiment 1). $A$, Mean \pm SEM percentage of freezing per 2 min period across the $5 \mathrm{~d}$ of extinction (open squares, saline; filled circles, naloxone). $B$, Mean \pm SEM percentage of freezing during the first 4 min before $C S$ onset on day 1 and average freezing across the $5 \mathrm{~d}$ of extinction training for the groups described in $A$ (open squares, saline; filled circles, naloxone), as well as freezing during a drug-free test (Test 1) and a crossover test (Test II). SAL, Saline; NAL, naloxone.

groups $\left(F_{(1,14)}<1 ; p>0.05\right)$ in levels of freezing across this test. On the second test day (test II, crossover), rats received microinjections into the vlPAG before the test. Rats in group saline received a microinjection of naloxone, whereas rats in group naloxone received a microinjection of saline. One rat in group naloxone had developed an infection and was not tested. The question of interest here was whether microinjection of naloxone into the vlPAG of group saline would reinstate the extinguished freezing CR. It did not. Inspection of the panel shows that infusions of naloxone into the vlPAG of rats in group saline did not significantly increase freezing beyond that observed during the drug-free test, nor did they increase freezing relative to rats in group naloxone now tested under saline. Indeed, the statistical analysis confirmed that there was no significant difference between overall levels of freezing observed during test I (drug-free) and test II (crossover) $\left(F_{(1,13)}<1 ; p>0.05\right)$. There was no overall difference in levels of freezing between group naloxone and group saline, averaged across test I and test II $\left(F_{(1,13)}<1 ; p>\right.$ $0.05)$. Finally, and importantly, there was no interaction between days and group $\left(F_{(1,13)}<1 ; p>0.05\right)$. In other words, vlPAG microinjections of naloxone did not alter the expression of an already extinguished freezing CR.

This experiment has shown that microinjections of naloxone into the vlPAG impair the extinction of Pavlovian fear conditioning. However, these microinjections did not reinstate expression of already extinguished CR. It is worth commenting briefly on the apparent difference between the naloxone and saline groups during the first $4 \mathrm{~min}$ of the CS on day 1 of extinction (Fig. $2 A$ ). The naloxone animals displayed significantly more freezing than the saline animals in the first 4 min (independent groups $t$ test, $p<$ $0.05)$. The reason for the depressed performance in the saline animals during the first 2 min of the CS on day 1 is unclear but cannot explain the obtained effects of naloxone on extinction because this difference was absent during the remainder of the test period on day 1 (independent groups $t$ test, $p>0.05$ ), and, critically, the two groups did not significantly differ in overall levels of freezing on day 1 (independent groups $t$ test, $p>0.05$ ).

\section{Experiment 2: role of vlPAG opioid receptors in extinction of conditioned fear}

Experiment 1 shows that microinjections of naloxone into the PAG impair the development but not the expression of extinction of conditioned fear. Experiment 2 had two aims. The first aim was to confirm the reliability and extend the generality of the impairment of fear extinction by using a different set of parameters for CS exposures during extinction. In experiment 1 , rats received a single 10 min CS presentation per day during extinction. In the present experiment, rats received eight 2 min CS presentations. The second aim was to determine whether any impairment of extinction of the freezing CR produced by vlPAG infusions of naloxone would be manifest during a drug-free test. In experiment 1 , rats received $5 \mathrm{~d}$ of extinction before the drug-free test, and there were, not surprisingly, no differences between groups on the drug-free test. In the present experiment, rats received only two extinction sessions, which did not produce complete extinction of freezing and were then tested for freezing to the CS. Rats were trained to fear an auditory CS via pairing with a foot shock. The fear that had accrued to that CS was then extinguished over $2 \mathrm{~d}$. For half the rats (group naloxone), this extinction training occurred after microinjection of naloxone into the vlPAG, whereas for the remainder (group saline), it occurred after microinjection of saline. Rats were then tested for their fear reactions. The test was conducted drug-free.

\section{Histology}

Figure $1 B$ shows the location of microinjection tips for rats in experiment 2 . One animal in each group was excluded from the experiment because of incorrect cannula placement. Therefore, 14 animals were included in the analysis (group saline, $n=7$; group naloxone, $n=7$ ).

\section{Behavior}

Figure $3 A$ shows the mean \pm SEM levels of freezing during the eight 2 min CS presentations across the $2 \mathrm{~d}$ of extinction training. Figure $3 B$ shows freezing during the $4 \mathrm{~min}$ immediately before the first CS on day 1 of extinction, as well as the average freezing per day across the $2 \mathrm{~d}$ of extinction training (Extinction) and on the test day (Test Drug Free). Inspection of Figure 3 indicates that microinjections of naloxone into the vlPAG did not alter levels of contextual freezing observed during the 4 min pre-CS period on day 1 . Indeed, there was no statistically significant difference between groups in levels of pre-CS freezing $\left(F_{(1,12)}<1 ; p>0.05\right)$. The eight 2-min CS presentations resulted initially in robust freezing and eventually in the extinction of conditioned freezing. This extinction was significantly reduced by vlPAG infusions of naloxone. There was a main effect for group so that there was significantly greater freezing across extinction training among group naloxone versus group saline $\left(F_{(1,12)}=10.2 ; p<0.01\right)$. There was a main effect for day so that there was significantly greater freezing on day 1 of extinction than on day $2\left(F_{(1,12)}=\right.$ $41.5 ; p<0.0001)$. Finally, there was also a group $\times$ day interac- 


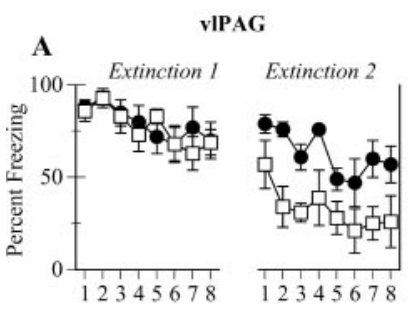

CS Presentation

$$
\text { B }
$$

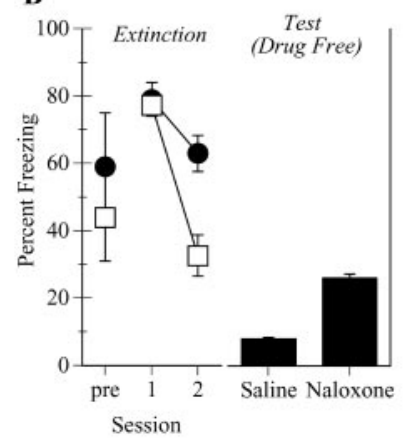

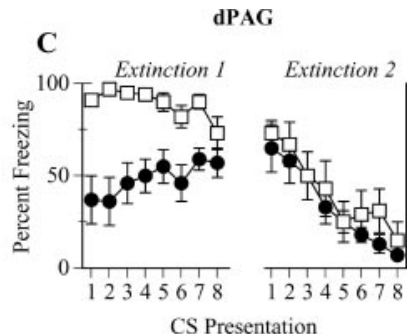

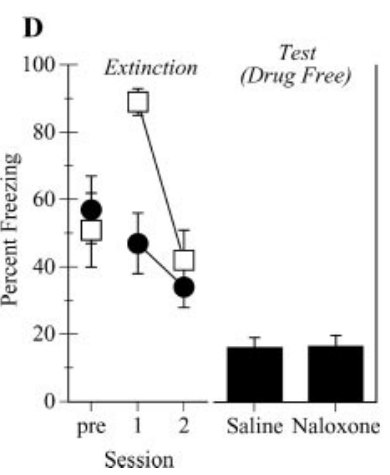

Figure 3. Role of opioid receptors in VIPAG (experiment 2) and IPAG (experiment 3) in extinction of conditioned freezing. $A$, Mean \pm SEM percentage of freezing per 2 min CS presentation across the $2 \mathrm{~d}$ of extinction (open squares, saline; filled circles, naloxone). $B$, Mean $\pm S E M$ percentage of freezing during the first $4 \mathrm{~min}$ before $C S$ onset and average freezing across extinction training for the groups described in $A$, as well as freezing during a drug-free test (experiment 2). C, Mean \pm SEM percentage of freezing per $2 \mathrm{~min}$ (S presentation across the $2 \mathrm{~d}$ of extinction (open squares, saline; filled circles, naloxone; experiment 3). D, Mean \pm SEM percentage of freezing during the first $4 \mathrm{~min}$ before $(S$ onset and average freezing across extinction training for the groups described in ( (open squares, saline; filled circles, naloxone), as well as freezing during a drug-free test (experiment 3).

tion $\left(F_{(1,12)}=10.8 ; p=0.01\right)$ so that the extinction of freezing was significantly greater among group saline compared with group naloxone. The levels of freezing on the test in Figure $3 B$ indicate that the differences between group saline and group naloxone were preserved on the drug-free test. Indeed, the analysis revealed that group naloxone showed significantly more freezing on the test than group saline $\left(F_{(1,12)}=48.3, p<0.001\right)$. The results of this experiment confirm that microinjections of naloxone into the vlPAG impair the extinction of a freezing CR and also show that this impairment is manifest during a drug-free test.

\section{Experiment 3: role of dPAG opioid receptors in extinction of conditioned fear}

The midbrain PAG is organized as a series of four longitudinal columns located dorsomedial, dorsolateral, lateral, and ventrolateral to the cerebral aqueduct that exert differential control over defensive behaviors (for review, see Carrive, 1993). For the present purposes, it is important to note that both dorsal PAG and vlPAG have been implicated in the species-specific defense response of freezing. Focal electrical stimulation of either dPAG or vlPAG produces freezing (Vianna et al., 2001), and reexposure to contextual stimuli previously paired with a foot shock elicits activation of the vlPAG and a smaller activation of the dPAG (Carrive et al., 1997). Although the defensive behaviors controlled by the APAG and vlPAG are otherwise distinct, it is possible that the effects of opioid receptor antagonists on the extinction of conditioned freezing may not be specific to the vlPAG, and similar results might be obtained if naloxone were microinjected into the dorsal PAG. This is especially important given that any diffusion of the microinjected naloxone was most likely toward dorsal aspects of the PAG. Therefore, experiment 3 studied the neuroanatomical specificity of opioid receptor regulation of the extinction of conditioned freezing by examining the effects of infusions of naloxone into the $\mathrm{dPAG}$ on that extinction.

\section{Histology}

Figure $1 C$ shows the location of microinjection tips for rats in experiment 3. Two animals in each group were excluded from the experiment because of incorrect cannula placement. Therefore, 12 animals were included in the experiment (group saline, $n=6$; group naloxone, $n=6$ ).

\section{Behavior}

Figure $3 C$ shows the mean \pm SEM levels of freezing during the eight 2 min CS presentations across the $2 \mathrm{~d}$ of extinction training. Figure $3 D$ shows freezing during the $4 \mathrm{~min}$ immediately before the first CS, as well as the average freezing per day across the $2 \mathrm{~d}$ of extinction training (Extinction) and on the test day (Test Drug Free). Inspection of Figure 3 indicates that microinjections of naloxone into the dPAG did not alter levels of contextual freezing observed during the $4 \mathrm{~min}$ pre-CS period on day 1 . Indeed, there was no statistically significant difference between groups in levels of pre-CS freezing $\left(F_{(1,10)}<1 ; p>0.05\right)$. The eight 2 min presentations of the CS resulted initially in robust freezing and eventually the extinction of conditioned freezing. Interestingly, this freezing was reduced by dPAG infusions of naloxone on day 1 but not on day 2. The analysis showed that there was a main effect for group so that there was significantly less freezing across extinction training among group naloxone versus group saline $\left(F_{(1,10)}\right.$ $=8.9 ; p=0.01)$. There was also a main effect for day so that there was significantly greater freezing on day 1 of extinction than on day $2\left(F_{(1,10)}=19.3 ; p<0.01\right)$. Finally, there was a group $\times$ day interaction $\left(F_{(1,10)}=5.3 ; p=0.04\right)$ so the extinction of freezing was significantly greater among group saline compared with group naloxone. In contrast to experiment 2 , in which the source of this interaction was the increased freezing of group naloxone on day 2, the source of this interaction in the present experiment was clearly the decreased freezing of group naloxone on day 1 . Importantly, there were no significant differences between group saline and group naloxone on the drug-free test $\left(F_{(1,10)}<1 ; p>\right.$ 0.05). That is, dPAG infusions of naloxone did not impair the development of extinction of freezing.

This experiment has shown that microinjections of naloxone into the dPAG do not impair the extinction of Pavlovian fear conditioning as indexed by freezing. Indeed, the effects of $\mathrm{dPAG}$ microinjections of naloxone were opposite to the effects of vlPAG microinjections. dPAG microinjections decreased freezing to the auditory CS on day 1 of extinction but had no effect on day 2 . These infusions also did not alter the extinction that accrued to the CS because there was no difference between groups in freezing on the drug-free test. In contrast, in experiment 2, vlPAG infusions increased freezing across days 1 and 2 during extinction and impaired the development of extinction because group naloxone showed increased freezing on the drug-free test compared with group saline. Therefore, this experiment has confirmed the neuroanatomical specificity of vlPAG opioid receptor contributions to the extinction of conditioned freezing.

Experiment 4: dose-response properties of vlPAG opioid receptor contributions to extinction of conditioned fear The aim of experiment 4 was to characterize the dose-response properties of vlPAG infusions of naloxone on fear extinction. 

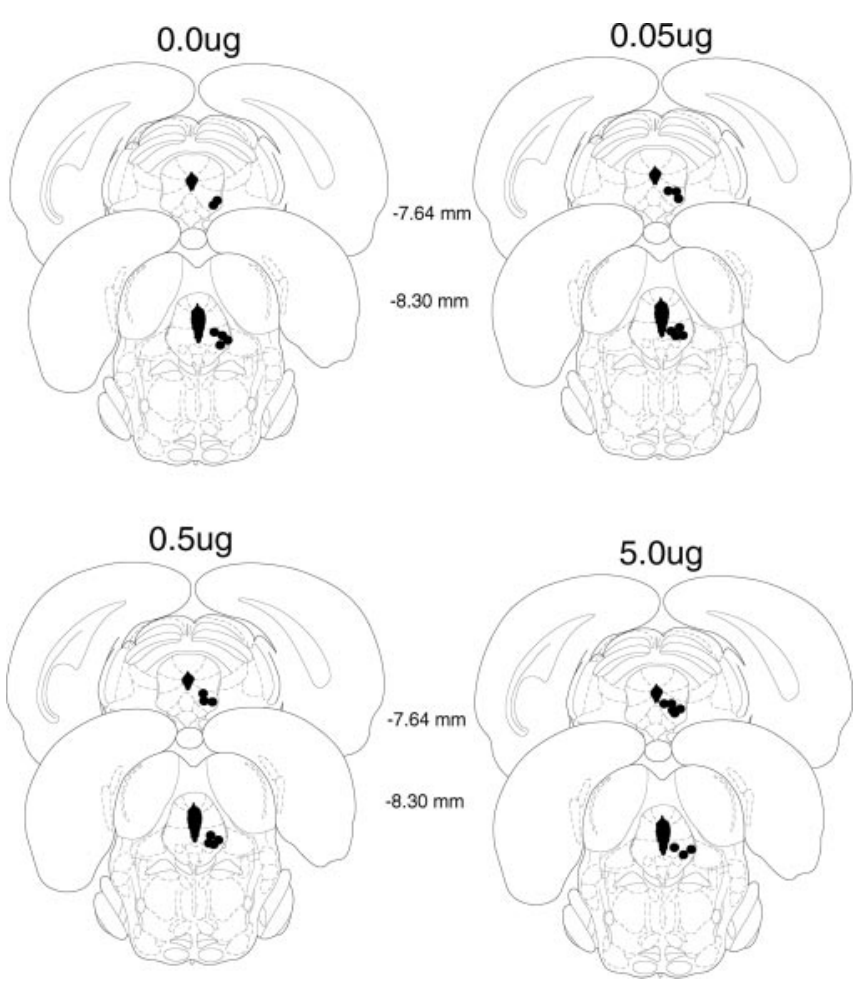

Figure 4. Cannula placement in the periaqueductal gray. Illustration of injection cannula placements in the periaqueductal gray for experiment 4 is shown. Placements represented are from all rats included in the final analysis. Atlas templates were adapted from Paxinos and Watson (1998) (distances in millimeters from bregma).

Although naloxone is a selective opioid receptor antagonist (but is not specific for opioid receptor subtypes), it remains possible that the effects of vlPAG naloxone in previous experiments might not have been achieved via actions at opioid receptors and/or that the differential effects of $\mathrm{PPAG}$ and vlPAG infusions might be related to dose. Therefore, in our final experiment, we studied the dose-response properties of vlPAG opioid receptor contributions to Pavlovian fear extinction. Rats were allocated to one of four groups. These groups received the same conditioning and extinction exposures as used in experiments 2 and 3 . The groups differed in the dose of naloxone infused into the vlPAG. These doses were $0.0,0.05,0.5$, and $5 \mu \mathrm{g}$ and correspond to $0,0.126$, 1.26, and $12.6 \mathrm{nM}$, respectively. After extinction training, rats were tested for their fear reactions to the CS. Only performance to the CS during this test was recorded and scored.

\section{Histology}

Figure 4 shows the location of microinjection tips for rats in experiment 4 . Five animals were excluded from the experiment because of incorrect cannula placement. Therefore, there were 27 animals included in the experiment (group $0 \mu \mathrm{g}$ of naloxone, $n=$ 6; group $0.05 \mu \mathrm{g}$ of naloxone, $n=7$; group $0.5 \mu \mathrm{g}$ of naloxone, $n=7$; group $5.0 \mu \mathrm{g}$ of naloxone, $n=7$ ).

\section{Behavior}

Figure 5 shows the mean \pm SEM percentage of observations scored as freezing across CS presentations on test. Inspection of the figure confirms that vlPAG infusions of naloxone impaired the extinction of the freezing CR and reveals that the effects of naloxone on fear extinction were dose-dependent. As the dose of naloxone infused into the vlPAG before extinction training increased, so too did the amount of freezing subsequently displayed on the drug-free test. This observation was confirmed by the

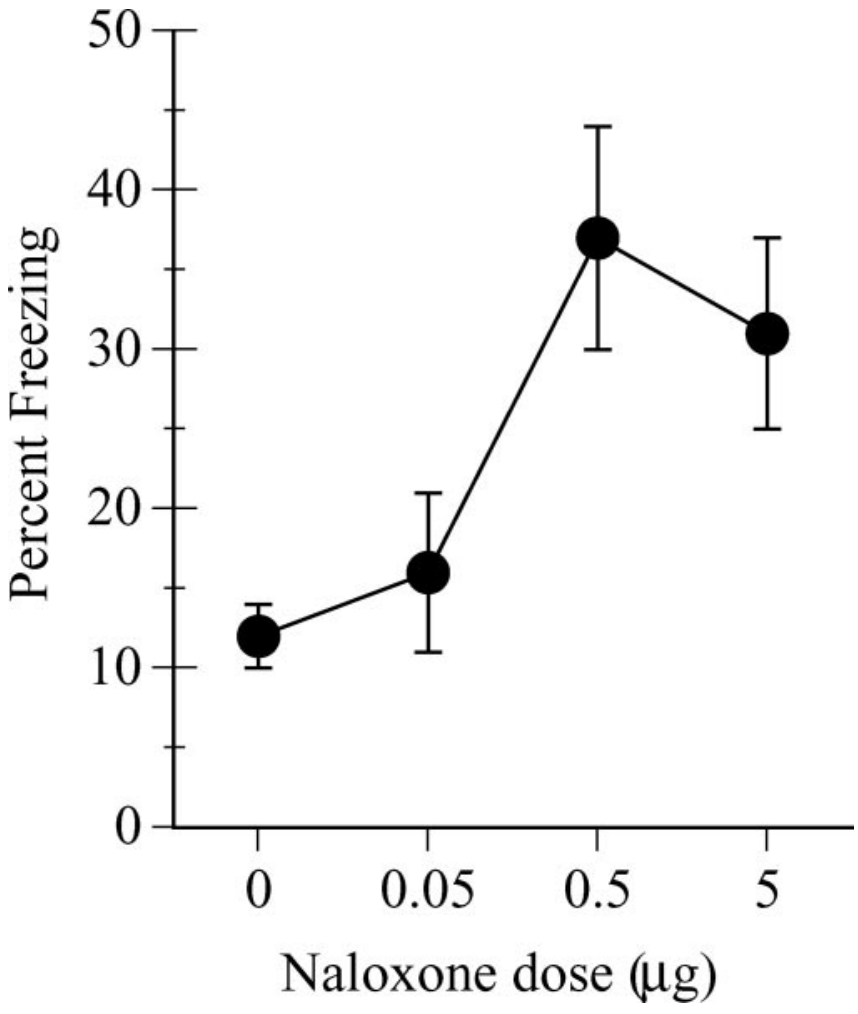

Figure 5. Dose-response properties of vIPAG opioid receptor contributions to extinction. Values are mean \pm SEM percentage of freezing on the test in experiment 4.

polynomial trend analysis, which showed a significant linear increase in freezing as the naloxone dose increased $\left(F_{(1,23)}=7.3\right.$; $p=0.01)$.

\section{Discussion}

Microinjection of the opioid receptor antagonist naloxone into the vlPAG impaired extinction of Pavlovian fear conditioning as indexed by freezing. This impairment was not attributable to state-dependent learning because impaired extinction was manifest regardless of whether rats were tested in the presence or absence of naloxone. Although important for the acquisition of extinction, vlPAG opioid receptors did not regulate the expression of extinction because microinjections of naloxone into the vlPAG failed to reinstate freezing to an already extinguished CS. This role for opioid receptors in the extinction of conditioned freezing was dose-dependent and specific to the vlPAG because microinjections of naloxone into the dPAG did not impair extinction. This dissociation between opioid receptor contributions in the vlPAG and dPAG to fear extinction is consistent with the differential control exerted by these PAG columns over defensive responses (Fanselow, 1991; Carrive, 1993; Vianna and Brandao, 2003). vlPAG microinjections of naloxone cannot have impaired extinction because they increased freezing per se and/or because they reproduced some component of the shock US (e.g., were painful or otherwise aversive). These explanations predict that vlPAG microinjections of naloxone should also increase freezing to any CS, as well as reinstate already extinguished fear. There was no evidence here for either of these predictions. Microinjections of naloxone into the vlPAG did not increase freezing during the $4 \mathrm{~min}$ pre-CS period in experiments 1 and 2 and did not increase freezing in rats that had already undergone extinction. This failure of vlPAG naloxone to affect the freezing CR in the absence of extinction is consistent with other published 
data showing that vlPAG infusions of opioid receptor antagonists do not inflate freezing per se (Fanselow, 1991). Instead, the present results support two novel conclusions. First, the midbrain PAG contributes to extinction of Pavlovian fear conditioning. Second, activity at opioid receptors in the vlPAG is critical for this contribution.

The contribution of vlPAG opioid receptors to fear extinction could be interpreted with reference to the other effects of opioid receptor antagonism on Pavlovian fear conditioning. Administrations of opioid receptor antagonists such as naloxone before conditioning facilitate acquisition of Pavlovian fear conditioning (Young and Fanselow, 1992; McNally et al., 2004). In addition, naloxone also prevents the associative blocking and overexpectation of fear. Briefly, McNally et al. (2004) trained rats in stage I to fear a context via pairings with a shock. In stage II, rats received auditory CS-shock pairings in that context. The previous context fear conditioning blocked fear from accruing to the auditory CS. Administration of naloxone before stage II prevented associative blocking. Likewise, McNally et al. (2004) trained rats to fear an auditory CS and a visual CS via separate pairings with a shock. In stage II, they arranged that the auditory and visual CSs were presented in compound and followed by the shock. This stage II training reduced fear of the auditory CS. That is, there was overexpectation of fear. Administration of naloxone before stage II prevented overexpectation. We have argued that opioid receptors regulate Pavlovian conditioning because they contribute to encoding of the discrepancy between the predicted outcome and the actual outcome of a conditioning trial (McNally et al., 2004). Learning depends critically on this discrepancy, so that learning occurs when this discrepancy is large (when there is a prediction error) and does not occur when this discrepancy is small (when there is no prediction error). Rescorla and Wagner (1972) provided a formal description of this discrepancy, $(\lambda-\Sigma V)$, in their learning rule; $\lambda$ is the asymptotic strength of association supported by the US, and $\Sigma V$ represents the summed $(\Sigma)$ associative strengths $(V)$ of all conditioned stimuli present on that conditioning trial.

We now suggest that opioid receptors contribute to error correction in emotional learning because their activation can be specifically identified with the $-V$ term in the discrepancy $(\lambda-$ $\Sigma V$ ). $-V$ is not the behavioral CR (i.e., freezing); instead, it is an inhibitory CR or signal, equal to the current associative strength of the target CS, that instantiates an error correction process to regulate the learning that accrues to that CS and other stimuli present on that trial, possibly by regulating the strength of the US inputs to the amygdala (Fig. 6). Identifying opioid receptor actions with an inhibitory signal, the $-V$ term in the discrepancy $(\lambda-\Sigma V)$, parsimoniously explains why opioid receptor antagonists exert opposing effects on the acquisition and extinction of Pavlovian fear conditioning. Naloxone impairs fear extinction but facilitates fear acquisition. During extinction, the shock US is omitted. At the start of extinction, the CS has a positive $V$ value. Extinction occurs because the discrepancy $(\lambda-\Sigma V)$ is negative. Our suggestion is that the actions of opioid peptides at their receptors can be identified with $-V$; thus during extinction, they provide the negative discrepancy necessary for extinction to occur. During extinction under naloxone the discrepancy $(\lambda-\Sigma V)$ is smaller, because $-V$ is smaller. Consequently, less extinction will accrue in naloxone-treated rats. Conversely, as acquisition of fear proceeds, the CS gains associative strength, and $-V$ increases. Naloxone facilitates acquisition of fear because it decreases $-V$ and thus increases the discrepancy $(\lambda-\Sigma V)$. The application of our suggestion to blocking is straightforward.

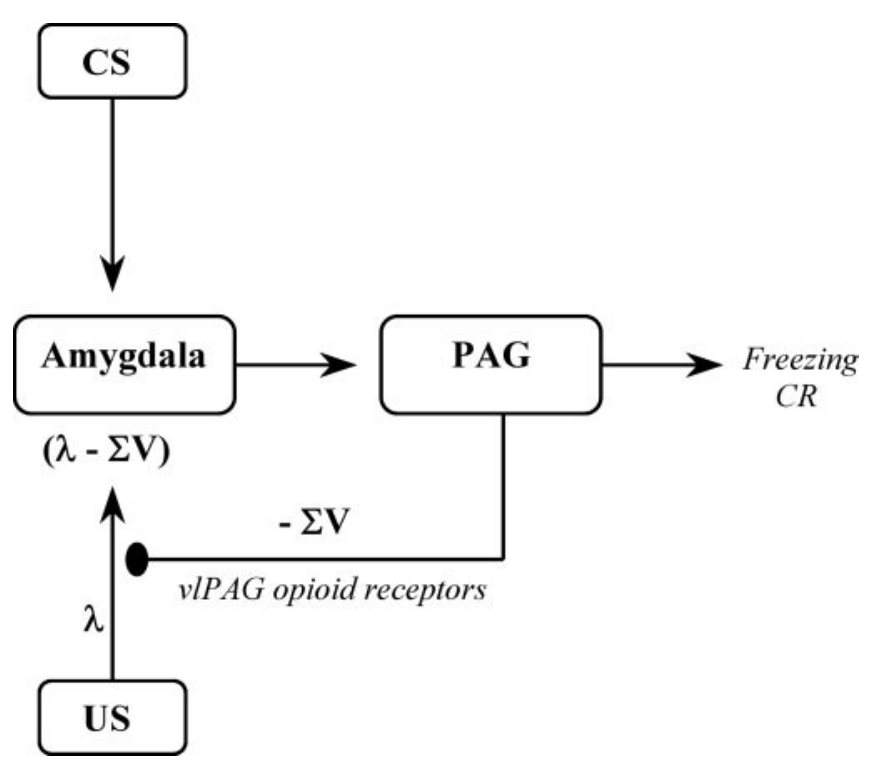

Figure 6. VIPAG opioid receptors regulate the learning that accrues to the CS and other stimuli present on a conditioning trial because they instantiate an associative error correction process that influences US information reaching the site of CS-US convergence in the amygdala. During nonreinforcement and whenever the discrepancy $(\lambda-\Sigma V)$ is negative, vIPAG opioid receptors provide an inhibitory signal that causes fear extinction.

Blocking occurs because $\Sigma V$ is larger, and the discrepancy $(\lambda-$ $\Sigma V)$ is smaller, during stage II among the pretrained group compared with control groups. Naloxone reduces the $-V$ value of the pretrained CS and therefore reduces $-\Sigma V$. This increases the stage II discrepancy $(\lambda-\Sigma V)$ and prevents blocking. Exactly the same logic explains the prevention of overexpectation. Overexpectation occurs because the $\lambda$ associated with the US during stage II is less than $\Sigma V$; hence, the $V$ value of each CS $\left(V_{\text {VISUAL }}\right.$ and $\left.V_{\text {AUDITORY }}\right)$ is reduced until $\lambda=\Sigma V$. Naloxone prevents overexpectation because it reduces $-\Sigma \mathrm{V}$. Overexpectation, like extinction, failed to occur because there is no negative discrepancy.

It follows from the present results that opioid receptor encoding of this inhibitory signal, or $-V$, occurs in the vlPAG. In other words, opioid receptors in the vlPAG regulate association formation during Pavlovian fear conditioning. Naloxone infusions into the vlPAG impaired fear extinction in the present experiments because they reduced the discrepancy between the actual and expected outcome of the conditioning trial by reducing the $-V$ value of the CS. Naloxone infusions into the vlPAG failed to reinstate responding to an already extinguished CS because vlPAG opioid receptors regulate the learning that occurs on a conditioning trial, not performance of the behavioral CR on that trial. This role for vlPAG opioid receptors in fear extinction is fundamentally different from the roles accorded the prefrontal cortex $(\mathrm{PFc})$ or amygdala in extinction. The PFc appears critical for restricting expression of the CR after extinction (Milad and Quirk, 2002) and the amygdala, especially the basolateral nucleus, critical for the learning that occurs during extinction (Falls et al., 1992). Opioid receptors in the vlPAG, according to our line of reasoning, provide the inhibitory signal that is learned about by the amygdala and initiates fear extinction. Because the PAG plays such a prominent role in CR production, it has not traditionally been associated with the regulation of association formation. However, one attractive feature of this suggestion is that a similar process operates in other Pavlovian conditioning preparations. In the rabbit nictitating membrane preparation, for example, extinction and associative blocking occur because of an 
inhibitory CR that has been identified with a projection from the cerebellum to the inferior olive. The inhibitory CR is not responsible for the behavioral CR (eye blink) but is responsible for extinction and blocking (error correction) because it depresses activity in the US pathway (climbing fibers) and alters the US information reaching the Purjinke cells and interpositus nucleus, the sites of CS-US convergence (Kim et al., 1998; Gluck et al., 2001; Medina et al., 2002). Likewise, in Pavlovian appetitive preparations, prediction errors (extinction and associative blocking) are associated with alterations in activity of midbrain dopamine neurons so that the omission of an otherwise expected reward suppresses activity of these cells (Schultz and Dickinson, 2000; Waelti et al., 2001; Tobler et al., 2003).

Our suggestion is that, during Pavlovian fear conditioning, activation of vlPAG opioid receptors contributes to detection of the discrepancy between the actual and expected outcome of the conditioning trial. vlPAG opioid receptors regulate the learning that accrues to the CS and other stimuli present on a conditioning trial because they instantiate an associative error correction process that influences US information reaching the site of CS-US convergence in the amygdala. During nonreinforcement, and whenever the discrepancy $(\lambda-\Sigma V)$ is negative (e.g., overexpectation), vlPAG opioid receptors provide an inhibitory signal that causes fear extinction (Fig. 6).

\section{References}

Amorapanth P, Nader K, LeDoux JE (1999) Lesions of periaqueductal gray dissociate-conditioned freezing from conditioned suppression behavior in rats. Learn Mem 6:491-499.

Carrive P (1993) The periaqueductal gray and defensive behavior: functional representation and neuronal organization. Behav Brain Res 58:27-47.

Carrive P, Leung P, Harris J, Paxinos G (1997) Conditioned fear to context is associated with increased Fos expression in the caudal ventrolateral region of the midbrain periaqueductal gray. Neuroscience 78:165-177.

Davis M (1992) The role of the amygdala in fear and anxiety. Annu Rev Neurosci 15:353-375.

De Oca BM, DeCola JP, Maren S, Fanselow MS (1998) Distinct regions of the periaqueductal gray are involved in the acquisition and expression of defensive responses. J Neurosci 18:3426-3432.

Falls WA, Miserendino MJ, Davis M (1992) Extinction of fear-potentiated startle: blockade by infusion of an NMDA antagonist into the amygdala. J Neurosci 12:854-863.

Fanselow MS (1991) The midbrain periaqueductal gray as a coordinator of action in response to fear and anxiety. In: The midbrain periaqueductal gray matter: functional, anatomical, and neurochemical organisation (DespaulisA, Bandler R, eds), pp 151-175, New York: Plenum.

Fanselow MS, LeDoux JE (1999) Why we think plasticity underlying Pavlovian fear conditioning occurs in the basolateral amygdala. Neuron 23:229-232.

Fendt M, Fanselow MS (1999) The neuroanatomical and neurochemical basis of conditioned fear. Neurosci Biobehav Rev 23:743-760.

Gluck MA, Allen MT, Myers CE, Thompson RF (2001) Cerebellar sub- strates for error correction in motor conditioning. Neurobiol Learn Mem 76:314-341.

Good AJ, Westbrook RF (1995) Effects of a microinjection of morphine into the amygdala on the acquisition and expression of conditioned fear and hypoalgesia in rats. Behav Neurosci 109:631-641.

Kim JJ, Krupa DJ, Thompson RF (1998) Inhibitory cerebello-olivary projections and blocking effect in classical conditioning. Science 279:570-573

Maren S (2001) Neurobiology of Pavlovian fear conditioning. Annu Rev Neurosci 24:897-931.

McNally GP, Westbrook RF (2003) Opioid receptors regulate the extinction of Pavlovian fear conditioning. Behav Neurosci 117:1292-1301.

McNally GP, Pigg M, Weidemann G (2004) Blocking, unblocking and overexpectation of fear: opioid receptors regulate Pavlovian association formation. Behav Neurosci 118:111-120.

Medina JF, Nores WL, Mauk MD (2002) Inhibition of climbing fibres is a signal for the extinction of conditioned eyelid responses. Nature 416:330-333.

Milad MR, Quirk GJ (2002) Neurons in medial prefrontal cortex signal memory for fear extinction. Nature 420:70-74.

Morgan MA, Romanski LM, LeDoux JE (1993) Extinction of emotional learning: contribution of medial prefrontal cortex. Neurosci Lett 163:109-113.

O’Brien RG, Kaiser MK (1985) MANOVA method for analysing repeated measures designs: an extensive primer. Psychol Bull 97:316-333.

Paxinos G, Watson C (1998) The rat brain in stereotaxic coordinates, Ed 4. Sydney: Academic.

Rescorla RA, Wagner AR (1972) A theory of Pavlovian conditioning: variations in the effectiveness of reinforcement and nonreinforcement. In: Classical conditioning II: current research and theory (Black AH, Prokasy WF, eds), pp 64-99. New York: Appleton Century Crofts.

Schultz W, Dickinson (2000) Neuronal coding of prediction errors. Annu Rev Neurosci 23:473-500.

Tobler PN, Dickinson A, Schultz W (2003) Coding of predicted reward omission by dopamine neurons in a conditioned inhibition paradigm. J Neurosci 23:10402-10410.

Vianna DM, Brandao ML (2003) Anatomical connections of the periaqueductal gray: specific neural substrates for different kinds of fear. Braz J Med Biol Res 36:557-566.

Vianna DM, Graeff FG, Brandao ML, Landeira-Fernandez J (2001) Defensive freezing evoked by electrical stimulation of the periaqueductal gray: comparison between dorsolateral and ventrolateral regions. NeuroReport 12:4109-4112.

Waelti P, Dickinson A, Schultz W (2001) Dopamine responses comply with basic assumptions of formal learning theory. Nature 412:43-48.

Walker DL, Ressler KJ, Lu KT, Davis M (2002) Facilitation of conditioned fear extinction by systemic administration or intra-amygdala infusions of D-cycloserine as assessed with fear-potentiated startle in rats. J Neurosci 22:2343-2351.

Walker P, Carrive P (2003) Role of ventrolateral periaqueductal gray neurons in the behavioral and cardiovascular responses to contextual conditioned fear and poststress recovery. Neuroscience 116:897-912.

Young SL, Fanselow MS (1992) Associative regulation of Pavlovian fear conditioning: unconditional stimulus intensity, incentive shifts, and latent inhibition. J Exp Psychol Anim Behav Process 18:400-413. 